\title{
Impact of Excess Weight Gain on Risk of Postpartum Infection in Class III Obesity
}

\author{
Courtney J. Mitchell, MD, $\mathrm{PhD}^{1}$ LaMani Adkins, $\mathrm{BS}^{2}$ \\ Anne Siegel, MD ${ }^{1}$ Sarah Dotter-Katz, MD, MMHPE ${ }^{1}$ \\ ${ }^{1}$ Department of Obstetrics and Gynecology, Duke University Medical \\ Center, Durham, North Carolina \\ ${ }^{2}$ Duke University School of Medicine, Durham, North Carolina \\ ${ }^{3}$ Department of Obstetrics and Gynecology, University of Mississippi \\ Medical Center, Jackson, Mississippi \\ ${ }^{4}$ Department of Obstetrics and Gynecology, University of South \\ Florida, Tampa, Florida
}

Am J Perinatol Rep 2020;10:e213-e216.
Ann Tucker, MD ${ }^{3}$ Haywood Brown, MD

Address for correspondence Sarah Dotters-Katz, MD, MMHPE, Department of Obstetrics and Gynecology, Duke University Medical Center, 2608 Erwin Road, Suite 220, Durham, NC 27705 (e-mail: sd132@duke.edu).

\begin{abstract}
Keywords

- morbid obesity

- gestational weight gain

- endometritis

- postpartum wound complication

Objective To assess the impact of gestational weight gain $>20$ pounds (more than Institute of Medicine [IOM] recommendations) on postpartum infectious morbidity in women with class III obesity.

Methods This is a retrospective cohort of term, nonanomalous singleton pregnancies with body mass index $\geq 40$ at a single institution from 2013 to 2017. Pregnancies with multiple gestation, late entry to care, and missing weight gain data are excluded. Primary outcome is a composite of postpartum infection (endometritis, urinary tract, respiratory, and wound infection). Secondary outcomes include components of composite, wound complication, readmission, and blood transfusion. Bivariate statistics compared demographics, pregnancy complications, and delivery characteristics of women exceeding IOM guidelines (GT20) with those who did not (LT20). Regression models were used to estimate adjusted odds of outcomes.

Results Of 374 women, 144 (39\%) gained GT20 and 230 (62\%) gained LT20. Primiparous, nonsmokers more likely gained GT20 $(p<0.05)$. No significant difference in other demographics. Among women who gained GT20, $10.4 \%$ had postpartum infectious morbidity compared with $3.0 \%$ in LT20 $(p<0.01)$. Wound infection is more common in the GT20 group ( 7.6 vs. $2 \%, p=0.02$ ). After adjustment, women who gained GT20 had threefold higher odds of postpartum infectious morbidity (adjusted odds ratio: $3.17,95 \%$ confidence interval: $1.17,8.60$ ).

Conclusion Women with class III obesity who gain more than the IOM recommends are at increased risk for postpartum infectious morbidity.
\end{abstract}

The prevalence of obesity among reproductive age women of 20 to 34 years is $35 \%$ and 35 to 44 years is $44 \%{ }^{1}$ The number of obese adults increased from 30.5 to $39.6 \%$ from 1999 to $2016 .^{2}$ As the rates of obesity have risen, so too have the obesity-related complications of pregnancy. Pregnant women with obesity are at increased risk of adverse pregnancy outcomes such as preeclampsia and gestational dia- betes. ${ }^{3}$ It has been demonstrated that as the class of obesity increases so does the risk of adverse pregnancy outcomes. ${ }^{4,5}$ In addition to amplified antepartum complications in pregnancy, obese women are also at increased risk of postpartum complications. Obese women have a two to four times increased risk of postpartum infection after cesarean delivery. 6,7 received

December 29, 2019

accepted

March 7, 2020
DOI https://doi.org/

10.1055/s-0040-1715165. ISSN 2157-6998.
Copyright $\odot 2020$ by Thieme Medical Publishers, Inc., 333 Seventh Avenue, New York, NY 10001, USA. Tel: +1(212) 760-0888.
License terms

()(1) $\Theta \circledast$ 
The Institute of Medicine (IOM), now known as the U.S. National Academy of Medicine, recommends women with any obesity, that is, body mass index $(\mathrm{BMI}) \geq 30 \mathrm{~kg} / \mathrm{m}^{2}$, gain 11 to 20 pounds in pregnancy. It estimated that approximately $50 \%$ of obese women gain more than what is recommended by IOM. ${ }^{8,9}$ There are limited data on the impact of gestational weight on postpartum infection, especially among women with class III obesity. As weight gain in pregnancy is variable and can be potentially optimized, expanding our understanding of the harms of excess weight gain in pregnancy is important. Therefore, we aimed to assess the impact of gestational weight gain $>20$ pounds (more than IOM recommendations) on postpartum infectious morbidity in morbidly obese women. We hypothesized that women who gain more than IOM recommendations will be at an increased risk of postpartum infectious morbidity.

\section{Materials and Methods}

We performed a retrospective cohort study of all singleton pregnancies at a tertiary care center with a BMI $\geq 40 \mathrm{~kg} / \mathrm{m}^{2}$ (class III obesity) between July 2013 and December 2017. Institutional Review Board approval was obtained from Duke University (IRB\# Pro00090712). All women with singleton pregnancy and BMI $\geq 40 \mathrm{~kg} / \mathrm{m}^{2}$ at entry to prenatal care who delivered at term (defined as $37^{0 / 7}$ weeks or later) were included. Exclusion criteria included multiple gestation, late entry to prenatal care at $>13^{6 / 7}$ weeks, fetal anomalies, intrauterine demise, and missing weight or BMI data. We also excluded women who lost weight in pregnancy. Trained chart abstractors performed standardized chart abstraction from the medical record. Data were collected on maternal demographics, medical and obstetrical history, labor and delivery events, and weight changes throughout pregnancy and postpartum. All women were managed per local protocol for obesity in pregnancy including detailed anatomy ultrasound, nutrition consultation, and counseling on recommended weight gain. Antibiotics were administered intrapartum for standard obstetric indications.

The exposure of interest was gestational weight gain. Gestational weight gain was defined as weight at delivery minus weight at entry to prenatal care. The primary outcome was a composite of postpartum infection which included wound infection, endometritis, urinary tract infection, and severe respiratory infection documented $>24$ hours after and within 6 weeks of delivery. Secondary outcomes included individual components of the composite, wound seroma, readmission, and blood transfusion.

Women who gained at or less than the IOM recommendations ( $\leq 20$ pounds) were compared with women who gained more than the IOM recommendations ( $>20$ pounds) using Kruskal-Wallis', chi-square, or Fisher's exact test as appropriate. A planned subanalysis was also performed among women with cesarean delivery, given the known association of cesarean delivery and postpartum infections. Multivariable logistic regression was used to estimate the true effect of gestational weight gain. Covariates in the regression model included those significant in the bivar- iate analysis and those with known associations to the outcome of interest. Logistic regression was used to estimate adjusted odds. Variables in the original model were BMI at delivery, parity, and tobacco use. STATA 13.1 (StataCorp, College Station, TX) was used to perform all analyses.

\section{Results}

Of 374 women, 230 (62\%) gained at or less than the IOM recommendations and 144 (39\%) gained more than IOM recommendations. Women gaining more than IOM recommendations were less likely to be multiparous and less likely to use tobacco (-Table 1). No significant difference in other baseline demographics was seen ( - Table 1 ). While there was no difference in median BMI at entry to care, median BMI at delivery (49.2 vs. 45.7, $p<0.01$ ) and median gestational weight gain ( 29 vs. 9 pounds, $p<0.01$ ) were both significantly higher among women gaining more than IOM recommendations as expected. Otherwise, obstetric and delivery characteristics did not differ between groups (-Table 2 ).

Overall, 22 women (5.9\%) had a postpartum infection. Among women who gained more than IOM recommendations, 10.4\% had postpartum infections compared with $3.0 \%$ among those who gained at or less than IOM recommendations $(p<0.01)$. Wound infection was also significantly more common among women who gained more than IOM recommendations ( 7.6 vs. $2 \%, p=0.02$ ). Among only women undergoing cesarean delivery, postpartum infection occurred more commonly among those with excess weight gain (20.8 vs. $5.4 \%, p<0.01)$. After adjusting for mode of delivery,

Table 1 Maternal demographics

\begin{tabular}{|l|l|l|l|}
\hline $\begin{array}{l}\text { Maternal } \\
\text { demographics }\end{array}$ & $\begin{array}{l}\text { LT20 } \\
\mathbf{N}=\mathbf{2 3 0}(\%)\end{array}$ & $\begin{array}{l}\text { GT20 } \\
\mathbf{N}=\mathbf{1 4 4}(\%)\end{array}$ & $p$-Value \\
\hline Median age (IQR) & $\begin{array}{l}29.3 \\
(25.4-34.7)\end{array}$ & $\begin{array}{l}29.9 \\
(26.5-33.6)\end{array}$ & 0.70 \\
\hline $\begin{array}{l}\text { Median BMI } \\
\text { at entry (IQR) }\end{array}$ & $\begin{array}{l}44.7 \\
(41.6-49.4)\end{array}$ & $\begin{array}{l}43.7 \\
(41.5-47.9)\end{array}$ & 0.17 \\
\hline Entry BMI > 50 & $51(22.1)$ & $22(15.3)$ & 0.11 \\
\hline Entry BMI >60 & $4(1.7)$ & $5(3.5)$ & 0.31 \\
\hline $\begin{array}{l}\text { Median GA at } \\
\text { entry to care (IQR) }\end{array}$ & $\begin{array}{l}9.2 \\
(8.0-11.6)\end{array}$ & $\begin{array}{l}10.0 \\
(8.0-11.4)\end{array}$ & 0.79 \\
\hline Multiparous & $150(65.2)$ & $72(50)$ & $<0.01$ \\
\hline Black race & $132(57.4)$ & $76(52.8)$ & 0.40 \\
\hline Hispanic ethnicity & $20(8.7)$ & $15(10.4)$ & 0.58 \\
\hline Private insurance & $105(45.7)$ & $70(48.6)$ & 0.60 \\
\hline Tobacco use & $27(11.7)$ & $7(4.9)$ & 0.03 \\
\hline $\begin{array}{l}\text { Recreational } \\
\text { drug use }\end{array}$ & $8(3.5)$ & $6(4.2)$ & 0.78 \\
\hline $\begin{array}{l}\text { Chronic } \\
\text { hypertension }\end{array}$ & $67(29.1)$ & $45(31.25)$ & 0.73 \\
\hline Type 2 diabetes & $19(8.3)$ & $15(10.4)$ & 0.58 \\
\hline
\end{tabular}

Abbreviations: BMI, body mass index; GA, gestational age; GT20, gained more than 20 pounds; IQR, interquartile range; LT20, gained 20 pounds or less. 
Table 2 Pregnancy outcomes

\begin{tabular}{|l|l|l|l|}
\hline $\begin{array}{l}\text { Pregnancy } \\
\text { outcomes }\end{array}$ & $\begin{array}{l}\text { LT20 } \\
\text { N=230 (\%) }\end{array}$ & $\begin{array}{l}\text { GT20 } \\
\text { N=144 (\%) }\end{array}$ & $p$-Value \\
\hline Preeclampsia & $35(15.2)$ & $22(15.3)$ & $>0.99$ \\
\hline $\begin{array}{l}\text { Preeclampsia with } \\
\text { severe features }\end{array}$ & $15(6.52)$ & $15(10.4)$ & 0.24 \\
\hline Gestational diabetes & $27(11.7)$ & $13(9.0)$ & 0.49 \\
\hline $\begin{array}{l}\text { Fetal growth } \\
\text { restriction }\end{array}$ & $8(3.5)$ & $10(6.9)$ & 0.14 \\
\hline Fetal macrosomia & $31(13.5)$ & $27(18.8)$ & 0.19 \\
\hline $\begin{array}{l}\text { Median GA at } \\
\text { delivery (IQR) }\end{array}$ & $\begin{array}{l}39.2 \\
(38.0-39.6)\end{array}$ & $\begin{array}{l}39.3 \\
(38.2-40.0)\end{array}$ & 0.11 \\
\hline $\begin{array}{l}\text { Median delivery } \\
\text { BMI (IQR) }\end{array}$ & $\begin{array}{l}45.7 \\
(43.4-50.7)\end{array}$ & $\begin{array}{l}49.2 \\
(46.8-53.6)\end{array}$ & $<0.01$ \\
\hline $\begin{array}{l}\text { Mean total weight } \\
\text { gain (pounds) }\end{array}$ & 7.5 & 31.8 & $<0.01$ \\
\hline Induction of labor & $80(34.8)$ & $42(29.2)$ & 0.31 \\
\hline Shoulder dystocia & $4(1.7)$ & $3(2.1)$ & $>0.99$ \\
\hline Chorioamnionitis & $19(8.3)$ & $13(9.1)$ & 0.85 \\
\hline $\begin{array}{l}\text { Median neonatal } \\
\text { birth weight (g) }\end{array}$ & 3,398 & 3,493 & 0.11 \\
\hline $\begin{array}{l}\text { Median estimated } \\
\text { blood loss at } \\
\text { delivery (mL) }\end{array}$ & $\begin{array}{l}400 \\
(250-750)\end{array}$ & $\begin{array}{l}500 \\
(250-800)\end{array}$ & 0.38 \\
\hline Cesarean delivery & $92(40)$ & $72(50)$ & 0.06 \\
\hline
\end{tabular}

Abbreviations: BMI, body mass index; GA, gestational age; GT20, gained more than 20 pounds; IQR, interquartile range; LT20, gained 20 pounds or less.

chorioamnionitis, and delivery BMI, women who gained more than IOM recommendations had threefold higher odds of postpartum infectious morbidity (adjusted odds ratio: $3.17,95 \%$ confidence interval: $1.17,8.60)$. When stratifying for cesarean delivery and controlling for delivery BMI and chorioamnionitis, women with excess gestational weight gain had 4.51-fold increased odds of postpartum infection (95\% confidence interval: $1.47,13.8$ ).

\section{Comment}

Our study demonstrates women with class III obesity who gain more weight than recommended by the IOM are at increased risk of postpartum infection compared with class III obese women who gain at or less than this recommendation, even when controlling for delivery BMI.

As obstetricians, we continue to grapple with the obesity epidemic. Counseling on gestational weight gain continues to be an important component of thorough preconception and prenatal counseling for obese patients. Recent studies have revealed strategies to prevent excessive gestational weight gain; these strategies include individualized nutrition program, focused and supervised prenatal exercise with proper intensity and duration measures, and goal-targeted behavior modifications. ${ }^{10,11}$ These interventions reportedly work best to prevent excessive gestational weight gain when performed simultaneously and should be routinely discussed during prenatal visits. Weight gain in pregnancy is poten- tially modifiable, and therefore, may be leveraged to improve maternal outcomes. Several studies have demonstrated the negative impact of excess gestational weight gain on pregnancy outcomes such as preeclampsia, gestational diabetes, cesarean delivery, birth weight, and preterm birth. ${ }^{9,12,13}$ Conversely, data exploring the detriments of excess gestational weight gain on postpartum infection are scarce. Data exist to demonstrate as BMI at the time of cesarean delivery increases, the rate of postpartum wound complications also increases. Smid et al compared postpartum wound complications among three BMI categories, nonobese (BMI <30), obese (BMI 30-45), and extreme obese (BMI $>45) .{ }^{5}$ Women with a BMI of 30 to $45 \mathrm{~kg}^{2}$ at the time of cesarean delivery had a $20 \%$ increased risk of wound infection, while women with BMI of $>45$ at the time of cesarean delivery had nearly four times increased risk of wound complication when compared with nonobese women. ${ }^{5}$ The rate of postpartum infection for the extreme obesity group was $9.8 \%$, which is similar to the infection rate we present for women who gained more than IOM recommendation. Our study looks exclusively at class III obesity (BMI $>40$ ), while Smid et al defined extreme obesity as a BMI $>45$, but notably the delivery BMI for both groups in our study was $>45$. In our study, we controlled for delivery BMI, and still noted weight gain to be associated with postpartum infection risk.

Other studies have noted increased risk of other obstetric infections in this population. Kabiru and Raynor demonstrated women with BMI $\geq 40$ at their first prenatal visit whose delivery weight was increased significantly had higher rates of chorioamnionitis. ${ }^{14}$ We did not note a difference in the rate of chorioamnionitis in this cohort. These disparate outcomes may be related to differences in the definitions of excess weight gain in our study ( $>20$ pounds) versus the aforementioned study ( $>15$ pounds). This study did not comment on postpartum infection rates for women with a BMI $\geq 40$ who gained more than 15 pounds.

A strength of this study is demonstration for the first time to our knowledge, an association between excess gestational weight gain and increased postpartum infection risk in morbidly obese women, even when controlling for BMI. An additional strength of this study is exclusive attention to pregnancy in women with class III obesity who have been shown to be at highest risk of postpartum wound morbidity. ${ }^{15,16}$ The average gestational age at entry to care in this cohort was in first trimester allowing a relatively accurate measurement of gestational weight gain.

We also acknowledge the limitations of our study. This study used BMI and weight at first obstetrics visit, not prepregnancy weight and BMI. Though we did require first visit to be in the first trimester, we did not have prepregnancy data. Though often women gain minimal weight in the first trimester, we believe this would be more likely to contribute to underestimation of total weight gain. Additionally, we dichotomized our study population to evaluate those who gained excess weight with those who did not because there is no evidence to suggest that women who gain less than IOM recommendations will have improved maternal or fetal outcomes. ${ }^{3}$ Our specific objective focused on the impact 
of excessive weight gain, and not the impact of pregnancy weight gain, in general, on infection risk. Further stratifying our study population into three groups, however, could have impacted our study results. Additionally, there are limited data regarding weight loss during pregnancy in this population, thus we excluded those who lost weight from the analysis. Weight lost could have affected our outcomes by serving as a confounder in the group, if the weight lost led women to fall $\mathrm{BMI}<40$. Moreover, we do not include data related to length of rupture of membranes prior to delivery, which may contribute to postpartum infectious morbidity, although the rate of endometritis was low in both groups. Furthermore, there was not a difference in the induction rate between the two study groups and our models controlled for mode of delivery. Our data do not identify women who were induced, but subsequently, went on to have a cesarean delivery despite this group being at high risk for postpartum infection. Additionally, between the time frame of our study, the CSOAP trial was published which revealed that adjunctive azithromycin in the setting of nonelective cesarean section was effective in reducing postoperative infection. ${ }^{17}$ The uptake of the findings did not occur universally at our institution; thus, we did not have access to antibiotic specifics. This potential change in practice could have impacted our results by broadly decreasing the infectious risk of some study participants. Finally, the retrospective nature of this study limits interpretation, thus we can only comment in association and not causation.

Overall, we present an association between excess gestational weight gain and increased risk of postpartum infection in women with class III obesity, even when controlling for delivery BMI. Though it has been well known that obesity functions as a risk factor for increased risk of infection, the susceptibility mechanism remains unclear. Similarly, the pathophysiology behind the association between excessive weight gain and increased risk of infection in morbidly obese women has yet to be described in the literature. As we continue to discover ways to reduce this risk for our patients, identifying this underlying mechanism could serve as a valuable use of resources and future direction for research. This study provides supplemental information for patients regarding the importance of optimizing weight gain in pregnancy. Further studies aimed at interventions to assist obese women stay within the recommended gestational weight gain targets are needed.

\section{Presentation Disclosure}

This abstract was presented as a poster at the Society of Maternal-Fetal Medicine's 39th Annual Pregnancy, February 11-16, 2019, in Las Vegas, NV.

\section{Conflict of Interest}

None declared.

\section{References}

1 Centers for Disease Control. Normal weight, overweight, and obesity among adults aged 20 and over, by selected characteristics: United States, selected years 1988-1994 through 20132016. In; 2017. Available at: https://www.cdc.gov/nchs/data/hus/ 2017/058.pdf. Accessed on September 19, 2019

2 Hales CM, Carroll MD, Fryar CD, Ogden CL. Prevalence of obesity among adults and youth: United States, 2015-2016. NCHS Data Brief 2017;(288):1-8

3 American College of Obstetricians and Gynecologists. ACOG committee opinion no. 548: weight gain during pregnancy. Obstet Gynecol 2013;121(01):210-212

4 El-Chaar D, Finkelstein SA, Tu X, et al. The impact of increasing obesity class on obstetrical outcomes. J Obstet Gynaecol Can 2013;35(03):224-233

5 Smid MC, Kearney MS, Stamilio DM. Extreme obesity and postcesarean wound complications in the Maternal-Fetal Medicine Unit Cesarean Registry. Am J Perinatol 2015;32(14):1336-1341

6 Leth RA, Uldbjerg N, Nørgaard M, Møller JK, Thomsen RW. Obesity, diabetes, and the risk of infections diagnosed in hospital and postdischarge infections after cesarean section: a prospective cohort study. Acta Obstet Gynecol Scand 2011;90(05):501-509

7 Wloch C, Wilson J, Lamagni T, Harrington P, Charlett A, Sheridan E. Risk factors for surgical site infection following caesarean section in England: results from a multicentre cohort study. BJOG 2012; 119(11):1324-1333

8 Gavard JA, Artal R. The association of gestational weight gain with birth weight in obese pregnant women by obesity class and diabetic status: a population-based historical cohort study. Matern Child Health J 2014;18(04):1038-1047

9 Goldstein RF, Abell SK, Ranasinha S, et al. Association of gestational weight gain with maternal and infant outcomes: a systematic review and meta-analysis. JAMA 2017;317(21): 2207-2225

10 Ruchat SM, Mottola MF, Skow RJ, et al. Effectiveness of exercise interventions in the prevention of excessive gestational weight gain and postpartum weight retention: a systematic review and meta-analysis. Br J Sports Med 2018;52(21):1347-1356

11 Nicodemus NA Jr. Prevention of excessive gestational weight gain and postpartum weight retention. Curr Obes Rep 2018;7(02): 105-111

12 Harper LM, Tita A, Biggio JR. The institute of medicine guidelines for gestational weight gain after a diagnosis of gestational diabetes and pregnancy outcomes. Am J Perinatol 2015;32(03):239-246

13 Voerman E, Santos S, Inskip H, et al; LifeCycle Project-Maternal Obesity and Childhood Outcomes Study Group. Association of gestational weight gain with adverse maternal and infant outcomes. JAMA 2019;321(17):1702-1715

14 Kabiru W, Raynor BD. Obstetric outcomes associated with increase in BMI category during pregnancy. Am J Obstet Gynecol 2004;191(03):928-932

15 Dotters-Katz SK, Feldman C, Puechl A, Grotegut CA, Heine RP. Risk factors for post-operative wound infection in the setting of chorioamnionitis and cesarean delivery. J Matern Fetal Neonatal Med 2016;29(10):1541-1545

16 Subramaniam A, Jauk VC, Figueroa D, Biggio JR, Owen J, Tita AT. Risk factors for wound disruption following cesarean delivery. J Matern Fetal Neonatal Med 2014;27(12):1237-1240

17 Tita AT, Szychowski JM, Boggess K, et al; C/SOAP Trial Consortium. Adjunctive azithromycin prophylaxis for cesarean delivery. N Engl J Med 2016;375(13):1231-1241 